\title{
Effects of simultaneous interpreting experience and training on anticipation, as measured by word-translation latencies
}

\author{
Agnieszka Chmiel \\ Adam Mickiewicz University in Poznań
}

This study aims to investigate the influence of interpreter training and conference interpreting experience on anticipation, as measured by wordtranslation latencies in a semantically constrained context. It involved professional conference interpreters, on the one hand, and, on the other, interpreter trainees being tested at the beginning and at the end of their two-year training programme. Both groups were asked to translate words embedded at the end of high-context constraint sentences (thus easily predictable), low-context constraint sentences or those appearing in isolation in both directions (from and to their native language). The data suggest that word-translation latency improves in the course of interpreter training but it is not enhanced further in the course of professional experience, whereas anticipation is not improved by either training or experience. All the participants, being late foreign language learners, manifested an advantage in native language comprehension by anticipating more in an $\mathrm{A}-\mathrm{B}$ versus a $\mathrm{B}-\mathrm{A}$ translation direction. The findings also suggest that professional interpreting experience might facilitate inhibition and lead to the selection of the appropriate translation equivalent.

Keywords: simultaneous interpreting, anticipation, translation, interpreter training, context constraint

Simultaneous interpreting may be considered to be an extreme case of bilingual processing, one in which interpreters concurrently engage in the analysis of the source language (SL) input and the expression of the same meaning in the target language (TL). Because interpreters often use almost all of their cognitive resources while interpreting (Gile 2009), they have to process language in an efficient manner in order to facilitate the production of the interpreted speech. To this end, they can use lexical anticipation, through which sentences are analysed 
incrementally and potential word matches are predicted and pre-activated on the basis of the semantic context of the sentence (Szewczyk \& Schriefers 2013). This process may result in their producing translation equivalents of the predicted words in the target language faster. It seems probable that the more often the interpreter uses this mechanism, the more efficient their interpreting becomes as a result of their reorganising cross-linguistic connections in the bilingual memory. This assumption was tested in the present study, which focused on the effects of interpreter training and experience on anticipation. Professional interpreters (with approximately 10 years of experience) and interpreting trainees (tested before and after a two-year training programme) were asked to translate words presented either in isolation or in a semantic context constraint. More specifically, the objective was to observe the ways in which training and experience modulate an interpreter's ability to use context to anticipate words by looking at wordtranslation latencies and response accuracy. In addition, language symmetry and the lack of a native-language comprehension advantage were expected in the group of professional interpreters. This was in fact the case because, according to their self-reports, they had been exposed to a similar amount of interpreting practice in each translation direction (i.e. from their native language to their foreign language and vice versa). Whenever such terms as 'interpreting' or 'interpreter' are mentioned in this article, they refer to oral translation; whenever such terms as 'translation' or 'translator' are mentioned, they refer to written translation. The only exception is 'word translation', which is used to name the experimental task, which, in line with the psycholinguistic research tradition (de Groot \& Poot 1997; Dijkstra et al. 2019; García et al. 2014), is understood to be the oral production of a translation equivalent of a given word.

\section{Anticipation and context effects in language processing}

Anticipation, used here interchangeably with prediction (see DeLong et al. 2014 for a review of terminology), involves the activation of a linguistic item before its perceptual input. It seems to be a natural mechanism in processing language according to electrophysiological data (Foucart et al. 2014; Foucart et al. 2015; Kutas et al. 2011) and eye-tracking data (Sedivy et al. 1999). Otten and Van Berkum (2008) review the psycholinguistic and neurolinguistic evidence that confirms the anticipation of syntactic structures, the grammatical roles of upcoming words, and the meaning and words from a specific semantic field. It would seem that language users benefit from analysing the incoming input at various levels in order to enable them to build meaning as soon as possible and to facilitate comprehension. 
What actually happens in the anticipation process (see Otten \& Van Berkum 2008) is much debated. Anticipation may be either a high-level, top-down process based on contextual constraint or a low-level, bottom-up process based on transitional probability (i.e. the predictability of a word in a given location based on corpus data) (McDonald \& Shillcock 2003). It is very difficult, though, to distinguish between the two processes. In fact, Frisson et al. (2005) claimed, on the basis of tracking eye movements in reading, that transitional probability contributes to the regular predictability mechanism based on contextual constraint. Thus, in the current study, no attempt will be made to distinguish between the effects of context and word predictability. Instead, anticipation is examined as a combined product or outcome of these two underlying processes. It is understood here as an increase in the availability (readiness) of associated information as a result of the perceived context (Van Berkum 2009). Anticipation can be both automatic (derived from lower-level word-based priming) and strategic (based on message-level representations of unfolding text) (DeLong et al. 2014; Federmeier \& Kutas 1999; Kutas \& Federmeier 2007). In other words, both automatic and conscious expectancy mechanisms are assumed to influence the process of anticipation (Tommola 1987; West \& Stanovich 1978) as more predictable words are "pre-activated, thereby making it easier to retrieve their lexical information" (Frank et al. 2015:7).

A substantial body of evidence shows that context facilitates word processing in bilinguals (Altarriba et al. 1996; Heij et al. 1996; Van Assche et al. 2013; van Hell 2005). Owing to facilitated anticipation, words embedded in semantically constraining sentences are recognised faster than those in neutral-context sentences. Semantic constraint effects have been found in studies with word-recognition tasks in the native language (L1) (Schwartz \& Kroll 2006), in studies employing L1-L2 and L2-L1 word-translation tasks performed by bilinguals without interpreting experience (van Hell and de Groot 2008) and by professional conference interpreters (Chmiel 2016). Semantic constraint effects have also been found in studies involving L1-L 3 word-translation tasks performed by language learners (Schwieter \& Ferreira 2014). Furthermore, eye-tracking studies of bilingual processing show that cross-linguistic activation is still present in highly constrained sentences; in other words, L1 words are still activated when processing L2 sentences with high-constraint contexts, and vice versa (Titone et al. 2011; Van Assche et al. 2011). This mechanism might be posited to be especially sensitive to interpreting practice. Interpreters might use anticipation to pre-activate translation equivalents in order to increase the efficiency of interpreting, especially in the case of word retrieval. Thus, one of the predictions of the present study is that anticipation will increase in proportion to increased exposure to interpreting (longer training or professional experience). 
Lexical anticipation (as understood in the present article) can be viewed in the light of the models of bilingual lexical processing. According to the Revised Hierarchical Model (RHM) by Kroll and Stewart (1994), L1 and L2 words have a common conceptual store and separate lexical representations. Because of the different strengths of links between the meaning and the form, L2-L1 translation occurs through a lexical route and is therefore faster, whereas L1-L2 translation takes longer because it goes through the semantic route (L2 words activate meanings and then meanings activate L1 translation equivalents) (Kroll \& Stewart 1994). Duyck and Brysbaert (2008) have challenged this position by claiming that word translation always involves both the lexical and the semantic route and that translation speed is modulated not by the type of route but by the strength of word-to-meaning and word-to-word mappings. In addition, according to the modified version of RHM, it is also possible that the meanings of $\mathrm{L}_{1}$ and $\mathrm{L}_{2}$ translation equivalents overlap to different degrees in line with the Distributed Feature Model (van Hell and de Groot, 1998). This latter model posits that word meanings are represented as sets of features. If more features are shared, the overlap in the meaning of translation equivalents is greater. Lexical anticipation in a crosslinguistic setting can thus be explained as follows in the light of the RHM incorporating both the strength of mappings assumption and the overlapping features of meaning assumption. If the sentence context is constraining, specific features of meaning are activated, which leads to the activation of a particular word. If the sentence context is non-constraining, no specific features of meaning can be activated and the specific word cannot be anticipated. This would explain context effects. In addition, if a word has stronger cross-linguistic connections to its translation equivalent following frequent previous co-activation (as a result of exposure to interpreting practice), it will be activated and produced faster by more experienced interpreters.

\section{Anticipation in simultaneous interpreting}

Anticipation is claimed to be an important part of conference interpreting and a crucial skill to be developed in the training of interpreters (Chernov 1979, 2004; Chmiel 2016; Moser-Mercer 1997; Seeber 2001). Interpreting scholars see anticipation primarily as a strategic process based on various sources and happening at various levels, such as lexis, syntax, suprasegmental features and pragmatics (Adamowicz 1989; Gile 2009; Kohn and Kalina 1996).

In the Interpreting Studies literature, anticipation has often been perceived as a directly observable product (Van Besien 1999). This means that the interpreter anticipates the word to be produced by the speaker and actually utters its 
translation equivalent before the speaker. However, anticipation can also happen even when the interpreter produces the translation equivalent after hearing the SL word (Lederer 1981). In this sense, anticipation is defined as a language production process that activates semantically based subsets in the lexicon (De Bot 2000) and "a particular mental model representation without it being completely induced yet through the speaker's sounds" (Vandepitte 2001:328).

Anticipation in interpreting is also often examined in relation to a specific pair of languages (Van Besien 1999). It is useful in interpreting, for instance, when the surface structure of the SL and the TL differ and, as a result, sentence-final elements in the SL have to be made sentence-initial in the translation. For example, a final verb in a German sentence has to follow the subject in an English sentence. If the interpreter delays the translation until the end of the source text sentence, the ensuing working memory load may compromise the quality of their interpreting. German has been particularly popular in studies of anticipation in simultaneous interpreting as it features frequent verb-final constructions. In his small-scale study on German-English interpreting, Seeber (2001) found numerous instances of correct anticipation of sentence-final verbs - the interpreter produced their translation equivalents before the speaker uttered the SL. Jörg (1997) found that verb anticipation in German was modulated by interpreting experience: interpreters were more successful at anticipation than trainees. The anticipation of German verbs was also better when it was the participants' A and not their B language (Jörg 1997; Kurz \& Färber 2003), which indicates a comprehension advantage in one's A language. Hodzik (2012) manipulated context (semantically constraining vs neutral) and transitional probability (high vs low) in shadowing and simultaneous interpreting tasks. She found that both context and transitional probability facilitated anticipation in shadowing, whereas only context facilitated anticipation in German-English simultaneous interpreting performed by advanced bilinguals and interpreters. Since she found a transitional probability effect in a follow-up study involving interpreting simple subject-verbobject sentences, Hodzik (2012) concluded that the importance of contextual constraint might increase with greater task difficulty and that language-pair specificity should always be taken into account when studying anticipation in simultaneous interpreting.

Using a different language pair, Bartłomiejczyk (2008) analysed anticipation as a strategy used by interpreting trainees. She found that it was more frequent in A-B (Polish-English) than in B-A (English-Polish) interpreting, which confirms that anticipation is easier when one is listening to one's native language.

Taken together, these studies show that anticipation is a frequent phenomenon in simultaneous interpreting; it is more efficient in the interpreter's A language, and it can be modulated by interpreting experience. 


\section{Effects of interpreter training and experience in linguistic tasks}

Owing to their continuing exposure to the specific use of two languages during simultaneous interpreting, interpreters are expected to gain some advantage in linguistic processing as a result of training and experience.

Few studies have focused on the effect of training by applying a withinsubject longitudinal design and examining the same trainees at the beginning and at the end of their training. This might be because of the difficulty inherent in such studies: the same participants have to be available after a year or two following the pre-study. In addition, groups of interpreters are usually small and some students drop out, which leads to the experimental groups being small sample sizes. Bartłomiejczyk (2010) found that after short, intensive practice the content component of the interpreting skills of ten trainees improved but their delivery worsened. Chmiel (2007) tested eight trainees on a semantic verbal fluency task and found that their performance improved as a result of training. However, as these were small-scale studies, such preliminary findings require more evidence from larger samples. The most comprehensive longitudinal study to date (Hervais-Adelman et al. 2015) involved 19 interpreting trainees who were tested before and after training with the functional magnetic resonance imaging (fMRI) method. The study found there to be several effects of training: trainees performed better and had shorter response latencies (i.e., they started interpreting sooner) following the training period. The neuroimaging data pointed to decreased activation in the caudate nucleus, a structure subserving multilingual and executive control, as a function of training in simultaneous interpreting. More advanced trainees may therefore manage lexical processing in two languages more efficiently than beginners.

Cross-sectional studies on the effect of professional interpreting experience are more numerous than longitudinal studies. They have employed a variety of research designs and have shown the advantage of professional interpreters over trainees in macro-processing source text (Sunnari 1995, 1996), restructuring syntax (Riccardi 1998), efficient information selection (Dillinger 1994; Liu et al. 2004), the successful use of background knowledge (De Feo 1993) and accuracy (Díaz-Galaz et al. 2015; Setton \& Motta 2007). Many of these studies show that professionals interpret faster or more efficiently than trainees.

In a study involving a word-translation task, García et al. (2014) tested professional translators, beginner trainees and another group of advanced trainees and found no main direction asymmetry (i.e., A-B translation latencies were not different from B-A latencies). However, detailed analyses revealed a B-A directional advantage in professionals when they processed both abstract and concrete words, whereas advanced trainees showed such asymmetry for concrete words 
only. These effects were explained by the possible reconfiguration of strengths in the semantic links between translation equivalents being modulated by increasing translation practice. Both advanced trainees and professionals outperformed beginners in a word-translation task, but there was no group effect between advanced trainees and professionals. This suggests that isolated word translation may be a task modulated by translation training, but then it may reach a plateau and as a basic word-processing phenomenon it may no longer be improved by translation experience. The present study will possibly help to extend this finding to interpreting.

As shown above, studies focusing on the effect of interpreting training and experience use a variety of research methods to compare interpreters and trainees. It is difficult to draw general conclusions because of the great diversity of designs and methodologies and a low replication rate. However, the emerging pattern is that interpreting performance improves with experience. None of the studies above compared trainees tested before and after training (in a within-subject design) with professionals on the same task in order to separate out the effect of training on the same sample and the effect of experience. The present study has used exactly this design to examine the ways in which training and experience modulate lexical anticipation.

\section{Directionality in interpreting}

Many international organisations and various national markets favour interpreting into one's native language (Seleskovitch \& Lederer 1989), although interpreting in both directions is a common practice in some national markets (Chernov 1992; Denissenko 1989; Lim 2005; Nicodemus \& Emmorey 2013).

The majority of studies on the directionality effect show superior performance in the B-A direction. Gran and Fabbro (1988) found that B-A interpreting was less demanding than interpreting into $B$, because of more efficient and automatic production in the native language. A-B interpreting was found to be of lower quality as a result of language-production deficits, awkward expressions, coherence breakdowns and more problematic fluency (Chang 2005; Donovan 2005; Mead 2005). Only one study to date has shown an A-B directionality advantage in verb anticipation (Kurz \& Färber 2003), while Tommola and Helevä (1998) showed there to be no directionality effect in information transmission.

In a study involving an isolated word-translation task, Christoffels, de Groot and Kroll (2006) found the directionality effect to have occurred only in the group of bilinguals and not in the groups of interpreters and language teachers. This was explained by proficient language use involved in both interpreting and 
language teaching. Using a similar task, De Bot (2000) compared the performance of intermediate, advanced and proficient bilinguals and found evidence of the L2-L1 directionality effect in the two less-proficient groups. These studies may suggest that language proficiency and a specific language use may cause cross-linguistic connections to be organised in the mental lexicon, in line with the modified RHM model (Kroll et al. 2002, 2010) referred to above. This could therefore eliminate or weaken the directionality effect in word-translation tasks performed by interpreters.

\section{The present study}

The present study attempts to examine the influence of simultaneous interpreting training and experience on anticipation skill, as shown in an empirical task that shares only a few characteristics with conference interpreting performed in a booth. The assumption underlying the present research is this: one way of examining linguistic processing during simultaneous interpreting is to break down this complex process into its component processes that can be tested in a controlled experiment. Word translation is one such basic process.

The study compared the same group of trainees both before and after training (a within-subject design) and the trainees after training with professional interpreters (a between-subject design). The participants were asked to translate words either embedded in sentences or in isolation. The study applied a mixed-factorial design with context (high constraint context, low constraint context, no context constraint) and direction (A-B vs B-A) as within-subject independent variables.

Our hypothesis was that the overall performance (word-translation accuracy and latency) would increase with training and experience. Thus, it was expected that the performance of the trainees after training would be better than that before training and that professionals would outperform trainees when they were tested after training. It was also predicted that anticipation (operationalised as wordtranslation latency for words embedded in sentences with high-constraint context as compared to low-constraint or no context) would be modulated by interpreting practice. Thus, a two-way group by context interaction was expected because the professionals were predicted to benefit from the high-constraint context more than the trainees. It was also predicted that this high-context facilitation would be more pronounced in the group of trainees after training than before training.

Translation direction was also manipulated in the study (A-B vs B-A). As shown in studies of unbalanced bilinguals (Kroll \& Stewart 1994), word translation into L1 might be faster than into L2. It was predicted that the behaviour of the interpreting trainees before training might be similar to that of the bilin- 
guals in the Kroll and Stewart (1994) study. On the other hand, since professionals reported being exposed to an equal amount of interpreting in both directions and owing to the proficient use of both languages by professionals and advanced trainees, no direction effect was expected in the performance of these groups, in line with Christoffels et al. (2006) and de Bot (2000). This means that a two-way group by direction interaction is expected in the study results.

To date, only one study has been conducted to compare the performance of bilinguals and interpreters in word translation in a task with a manipulated semantic constraint. Hodzik (2012) included both bilinguals and interpreters in her study, but her group of interpreters was not homogenous, being composed of seven interpreting trainees and four professional interpreters. Separate groups of interpreting trainees and professional interpreters were tested in the present study and the groups were larger and more homogenous. In addition, a within-subject design was applied in order to examine the effect of training. This helped to avoid issues in matching experimental samples typical of between-subject designs where individual factors, such as memory capacity or language proficiency, may come into play as confounding variables.

\subsection{Participants}

Forty-four participants took part in the present study. They included 20 interpreting trainees examined at the beginning and at the end of a two-year MA programme in conference interpreting and 24 professional interpreters.

The trainees included 14 females and 6 males from a graduate-level conference interpreter training programme at a university in Poland. Their mean age was 22 years $(S D=.88)$ before training and 24 years $(S D=1.1)$ after training. Their A language was Polish, their B language was English and 13 of them had some command of other languages (such as German, French or Spanish). None of them had had any interpreting experience greater than two days of ad-hoc amateur interpreting. Their training included approximately 500 contact hours devoted to practical interpreting practice over two years. In the before-training condition they were tested within the third or fourth week of their training and in the aftertraining condition they were re-tested two or three weeks before their final interpreting examination.

The professional interpreters included 13 females and 11 males. Their mean age was 38 years $(S D=8.37)$ and their self-reported mean professional experience was 13 years $(S D=8.12)$. Their A language was Polish, their B language was English and 11 of them knew other languages (such as Russian, French, German, Italian, Spanish and Swedish). They were all freelance interpreters who had been recruited through a translation agency and their mean self-reported number of 
conference interpreting days per month in the three years preceding the study was $6.39(S D=4.81)$.

All the participants were late L2 learners who had acquired English as their L2 in a school context. The L2 proficiency of the interpreter trainees was at least at the $\mathrm{C}_{1}$ level (according to the Common European Framework of Reference for Languages [CEFR], North 2014) as they all had to pass C1-level practical English exams in the course of their studies. The L2 proficiency of the professional interpreters was determined via LexTALE (Lemhöfer \& Broersma 2012) and their mean LexTALE score in English was 89.31 $(S D=9.31)$. Since, according to the CEFR, the $\mathrm{C}_{1}-\mathrm{C}_{2}$ level of English proficiency is commensurate with the LexTALE score of 80-100 (Lemhöfer \& Broersma 2012), the two groups of participants can be considered as having comparable L2 proficiency.

Both groups were equally exposed to both directions of interpreting ( $\mathrm{A}-\mathrm{B}$ vs $\mathrm{B}-\mathrm{A}$ ) in their training or professional practice. In a pre-study questionnaire, the interpreters were asked to estimate how much they interpret into their B. Their mean self-reported percentage of total work time spent interpreting into B was 51 $(S D=14.01$, range $15-80)$. The professional practice of bidirectional interpreting is also reflected in their training. The conference interpreting programme pursued by the trainees tested in this study included an equal number of classes devoted to each interpreting direction. Thus, it is safe to conclude that both groups were comparable regarding balanced exposure to both directions of interpreting.

\subsection{Materials}

The stimulus words and sentences used in the present experiment were selected from Kujałowicz et al. (2008). They included 39 English nouns and 39 Polish nouns matched for frequency, length and concreteness. The mean length in letters was 6.1 $(S D=1.02)$ for the English words and $6.28(S D=1.62)$ for the Polish words, whereas the mean length in syllables was $1.8(S D=.66)$ for the English words and $2.1(S D=.57)$ for the Polish words. The mean frequency per million was 22.02 $(S D=3.46)$ for the English words (according to the British National Corpus, 2007) and 21.72 $(S D=3.33)$ for the Polish words (according to the National Corpus of Polish) (Przepiórkowski et al. 2012). Kujałowicz et al. (2008) collected concreteness judgments among 50 proficient speakers of English as L2. All the experimental stimuli scored 6 or higher on a 7-point Likert scale in that norming, indicating a high level of concreteness.

Each word was embedded as a final word in a high-constraint context (HC) sentence and a low-constraint context (LC) sentence. This was modelled after van Hell (2005). Table 1 presents examples of the experimental materials. Kujałowicz et al. (2008) performed a probability cloze test to establish appropriate context 
constraints. Two rounds of such a norming study were needed to arrive at the desired number of stimulus sentences.

Table 1. Example of the English experimental materials

High-context constraint sentence

All her expensive shoes are made of LEATHER.

To keep off rabbits, the garden was surrounded by a FENCE.

They bought a new computer with a colour laser PRINTER.

In the shop there was no shop assistant behind the COUNTER.

They all stared at the lamp hanging from the CEILING.

\section{Low-context constraint sentence}

These innovative handcrafted products are made from LEATHER.

They were all sitting in front of the FENCE.

In the article you'll read about the new model of this PRINTER.

Please do not leave your possessions on the COUNTER.

He noticed a large wet spot on the CEILING.

Three sets of experimental materials for Polish and three sets for English were created. Each set contained 13 words in HC sentences, 13 words in LC sentences and 13 words presented in isolation with no context (NC). No word appeared in a given set twice and experimental conditions were randomised across sets. If a given word appeared in HC in set A, it appeared in LC in set B, and in NC in set $C$. Each participant was presented with one set only and did not see the same word twice.

\subsection{Procedure}

The experiment was programmed using E-Prime 2.0 software (Schneider et al. 2002). Verbal responses were measured by a serial response box equipped with a microphone. The order of the sets $(\mathrm{A}, \mathrm{B}$ or $\mathrm{C})$ and the order of the languages (English or Polish) were counterbalanced across the participants. The participants received oral and written instructions in the language of the experimental set. Each experimental set was preceded by a practice block to familiarise the participants with the experimental procedure. The practice block was repeated, if so requested by a participant.

In the sentence part of the experimental block, trials began with a fixation mark presented in the centre of the screen for $500 \mathrm{~ms}$. This was followed by a sentence displayed without the final word. The participants were instructed to read the sentence carefully and to press the space bar when finished. After they pressed, a target word appeared for translation into the microphone as quickly 
and as accurately as possible. The target word disappeared either when the verbal response was recorded by the serial response box or after 10,000 ms. This was followed by a blank screen and then another trial began. After the sentence part of the experimental block for each language, the participants filled in a pen-andpaper sentence-recognition task. They were asked to tick those sentences they had seen in the preceding part of the experiment. There were seven sentences, of which between two and five were correct, depending on the experimental set. This task was administered to make sure the participants were actually reading the sentences and processing their meaning so that potential semantic context effects could be observed.

In the word part of the experimental block the participants were asked to translate the words. They did not have to press the space bar because the words appeared automatically at the beginning of the trial and disappeared either when a verbal response was recorded or after 10,000 ms. After the sentence part and the word part in one language were completed, the participants repeated the whole procedure in the other language. The whole experiment lasted approximately 20 minutes per person.

\subsection{Data analysis}

The results of the sentence-recognition task were first analysed in order to eliminate response-time data from those experimental blocks in which participants insufficiently engaged in the semantic processing of sentences. It was decided to eliminate any score lower than 5 out of 7 . All the recognition scores for the group of interpreting trainees before training were above 5. The score for the PolishEnglish condition was $97.8 \%$ and the score for the English-Polish condition was $100 \%$. In the group of interpreter trainees after training, one score was below 5 ; the observations for that particular participant in a relevant condition were deleted from further analysis. The total recognition scores for both directions were $97.8 \%$.

There were no scores below 5 in the group of professional interpreters. Their overall recognition score was $98.2 \%$ for the Polish-English condition and $99.4 \%$ for the English-Polish condition. Further on, seven outlying observations were eliminated from the analysed reaction times on the basis of the visual inspection of residuals. (Visual inspection of outliers makes it possible to have a more finegrained trimming of data than the more commonly used exclusion of outliers outside the range of $+/-2.5$ standard deviations.) The outliers included 3 observations for trainees before training, 2 observations for trainees after training and 2 for professional interpreters. All these removed reaction times were shorter than $45 \mathrm{~ms}$. 
The data were analysed by creating linear mixed effects models with the lme 4 package (Bates 2007) of R ( $R$ Development Core Team 2013). Linear mixed effects modelling handles unbalanced data better than the traditional analysis of variance; and by including participants and items as random effects, it can capture individual differences between participants and experimental items at the same time (unlike ANOVA's separate F1 and F2 analyses) (Barr et al. 2013; Bates et al. 2015).

\subsection{Results}

Since group type was a within-subject variable when comparing trainees before and after training and a between-subject variable when comparing trainees after training with professionals, separate analyses were conducted for those two major comparisons - the former focusing on the effects of training and the latter on the effects of expertise. However, the tables and graphs below present data for all three experimental groups. The means are presented for the HC first, then for the NC condition and for the LC last. Since the NC condition was the baseline, the presentation of the results in this sequence makes it easier to see HC gain (the difference between the HC and the NC condition) and LC cost (the difference between the LC and NC condition).

\subsubsection{Effects of training}

The results of the interpreting trainees before and after training were first compared to see how training modulated their performance. The accuracy rate (the percentage of correct translations in the total translations) for trainees was $87.3 \%$ before training and $93.4 \%$ after training. Table 2 and Figure 1 present the accuracy rates for all the experimental conditions and groups. A generalised linear mixed model was fitted to see the group differences on accuracy data. The model included items and participants as variance components and group, context, direction and all interactions as fixed effects. The Laplace approximation was used to estimate $p$ values and sliding contrasts were used to estimate parameters. The analysis showed a significant group effect $(\beta=.80, S E=.21, z=6.00, p<.001)$, with better performance by the trainees after training as compared to their results before training - a significant difference between $\mathrm{HC}$ and NC conditions $(\beta=.52$, $S E=1.16, z=3.24, p<.01)$, with greater accuracy in an $\mathrm{HC}(91.8 \%)$ than in an NC condition (87.7\%); a significant difference between NC and LC conditions $(\beta=.44, S E=.15, z=2.82, p<.01)$, with greater accuracy in the LC $(91.4 \%)$; and a significant interaction between two levels of context (HC and NC) and direction $(\beta=.67, S E=.32, z=2.09, p<.05)$ (accuracy in the L1-L2 direction was $90.9 \%$ for 
$\mathrm{HC}$ and 89.6 for NC, while accuracy in the $\mathrm{L}_{2}-\mathrm{L} 1$ direction was $92.7 \%$ for $\mathrm{HC}$ and $85.8 \%$ for NC).

As predicted, the trainees performed better after training and when interpreting words embedded in sentence contexts as opposed to the NC condition. This suggests that training modulates translation accuracy and that trainees use context constraint to their advantage both before and after training. The context-bydirection interaction suggests that context modulated accuracy more in the B-A direction and did not change accuracy rates much in the A-B direction.

Table 2. Accuracy rates (percentage of correct translations in each condition)

\begin{tabular}{lrrrrrrrr}
\hline & \multicolumn{3}{c}{ L1-L2 } & & \multicolumn{3}{c}{ L2-L1 } \\
\cline { 2 - 4 } \cline { 8 - 9 } & HC & \multicolumn{1}{c}{ NC } & LC & & HC & NC & LC \\
\hline Trainees before training & 87.69 & 86.53 & 88.07 & & 90.38 & 82.30 & 88.84 \\
Trainees after training & 94.23 & 92.69 & 94.61 & & 95.00 & 89.47 & 94.23 \\
Professionals & 100.00 & 100.00 & 100.00 & & 100.00 & 100.00 & 100.00 \\
\hline
\end{tabular}

Note: HC - high-context constraint, NC - no-context, LC - low-context constraint.
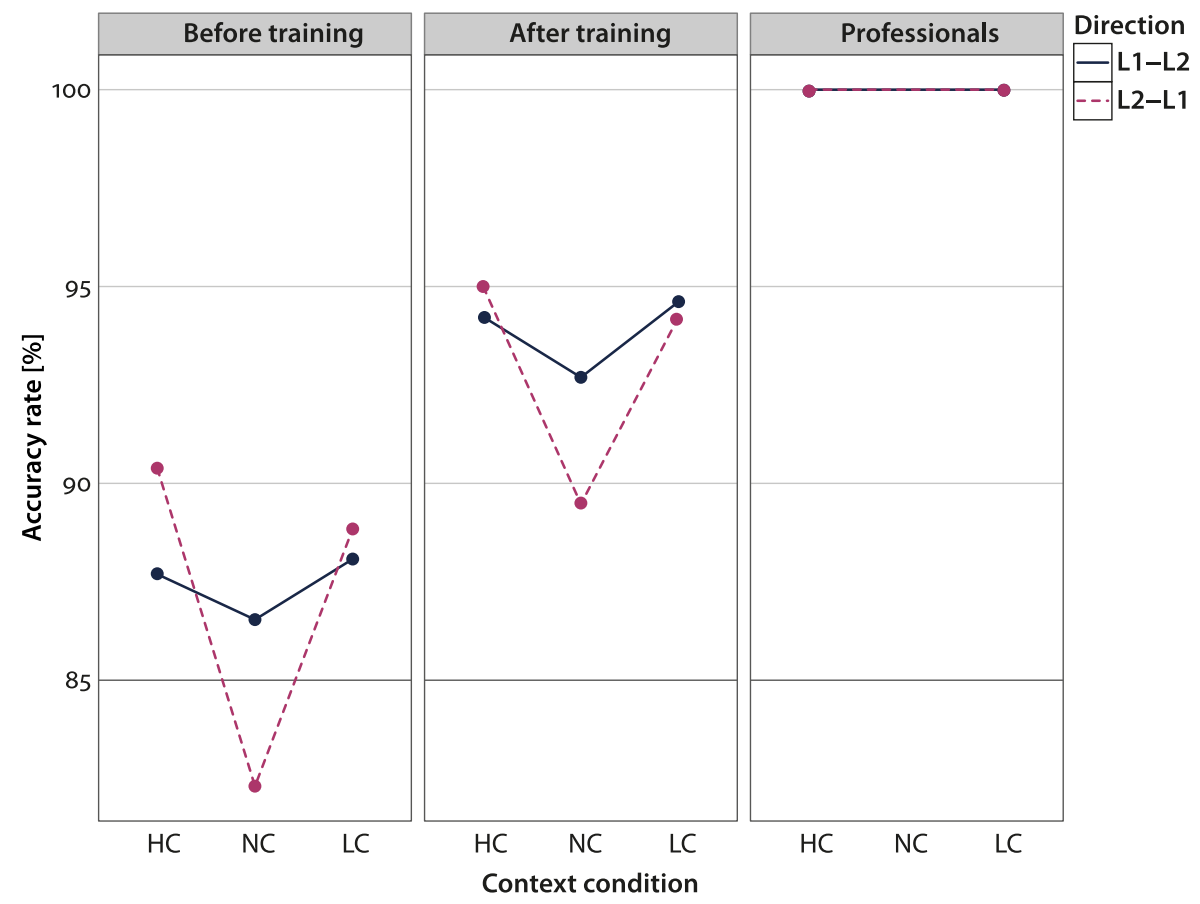

Figure 1. Accuracy rates (in percent) 
To analyse translation latencies, the reaction times only from accurate trials were considered. A linear mixed model was fitted with Satterthwaite approximations to establish $p$ values and with sliding contrasts to estimate parameters. The model included group, context, direction, two-way and three-way interactions between the factors as fixed factors, and items and participants as random intercepts. The reaction times were log-transformed to obtain a normal distribution of data. Thus, the coefficients and standard errors reported in the description of the model reflect log-transformed reaction times. However, for the sake of convenience, means and standard errors for all the groups and conditions are presented without $\log$ transformations (Table 3 ). The results are also presented in Figure 2.

Table 3. Mean translation latencies (in ms) and standard deviations (in parentheses) in all experimental conditions

\begin{tabular}{lcccccccc}
\hline & \multicolumn{3}{c}{ L1-L2 } & & \multicolumn{3}{c}{ L2-L1 } \\
\cline { 2 - 4 } \cline { 8 - 9 } & HC & NC & LC & & HC & NC & LC \\
\hline Trainees before & 756 & 1117 & 1154 & & 785 & 962 & 1048 \\
training & $(455)$ & $(702)$ & $(734)$ & & $(346)$ & $(529)$ & $(477)$ \\
Trainees after training & 708 & 1010 & 1177 & & 755 & 990 & 986 \\
& $(521)$ & $(391)$ & $(857)$ & & $(446)$ & $(465)$ & $(510)$ \\
Professionals & 733 & 994 & 1012 & & 761 & 944 & 1016 \\
& $(294)$ & $(291)$ & $(295)$ & & $(435)$ & $(427)$ & $(479)$ \\
\hline
\end{tabular}

The analysis revealed the main effect of group $(\beta=.04, S E=0.01, t=2.76$, $p<.01)$. Before training $(M=969, S D=575)$ the trainees were $32 \mathrm{~ms}$ slower than after training $(M=937, S D=577)$. Significant differences $(\beta=.04, S E=0.02$, $t=20.78, p<.001)$ were found between the HC $(M=751, S D=447)$ and the NC conditions $(M=1020, S D=534)$, as well as between the NC and LC conditions $(M=1090, S D=668)(\beta=.05, S E=0.02, t=3.14, p<.05)$. Thus, the overall $\mathrm{HC}$ gain was $269 \mathrm{~ms}$ as compared to the baseline NC condition and the overall LC cost was $70 \mathrm{~ms}$ as compared to the same baseline.

There was also the main effect of direction $(\beta=.04, S E=0.01, t=2.82, p<.001)$, with B-A translation latencies $(M=918, S D=478) 68 \mathrm{~ms}$ shorter than A-B latencies $(M=986, S D=659)$. This suggests that, in general, translation into $\mathrm{A}$ is faster than into B. Similarly to the accuracy data, a significant interaction was found between two levels of context (HC and $\mathrm{NC}$ ) and direction $(\beta=.15, S E=0.03$, $t=4.31, p<.001$ ) (translation latencies in the L1-L2 direction were $731 \mathrm{~ms}$ for HC and $1061 \mathrm{~ms} \mathrm{NC}$, whereas in the L2-L1 direction they were $769 \mathrm{~ms}$ for HC and $976 \mathrm{~ms}$ for NC). This suggests more efficient anticipation when processing sentences in A than when doing so in B. 


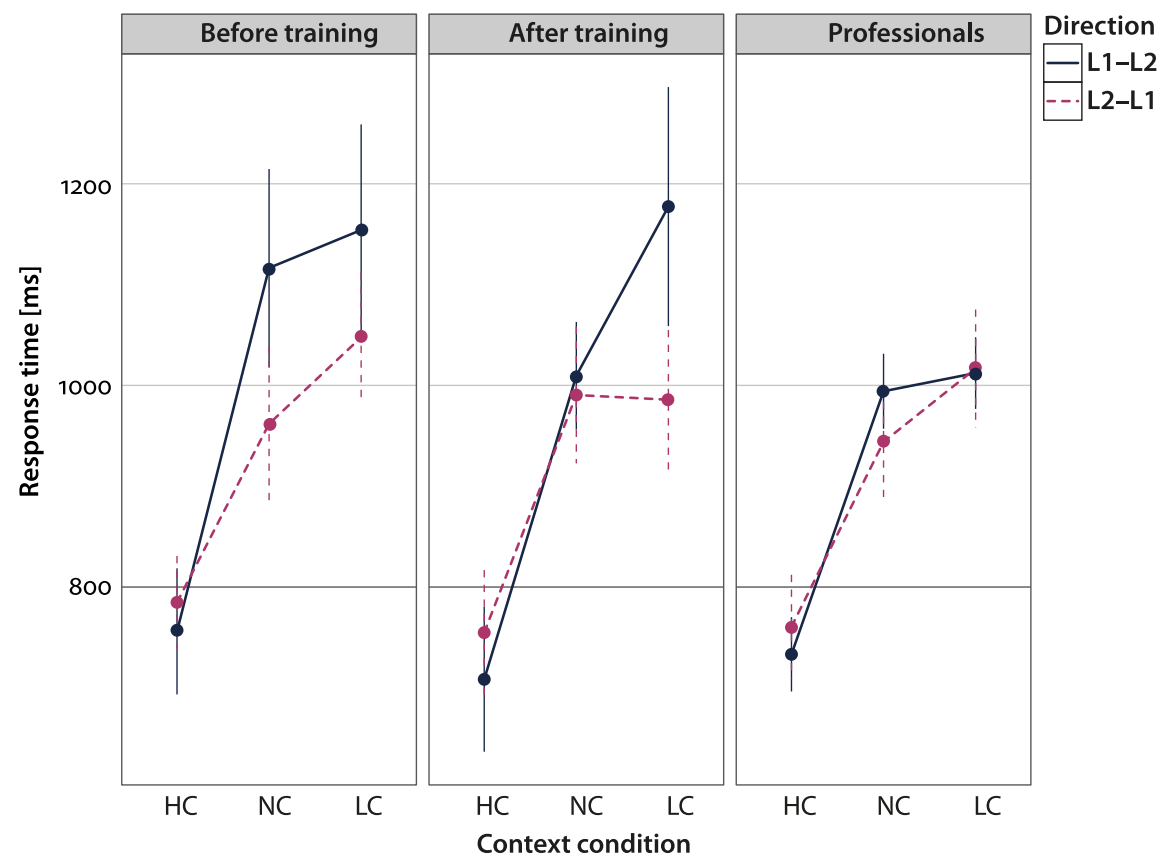

Figure 2. Translation latencies by condition. Error bars are +/- standard errors of means

Other differences specified in the contrasts turned out to be non-significant. Contrary to my predictions, no group by context interaction was found, which means that the study offers no evidence to show that trainees make more efficient use of $\mathrm{HC}$ to anticipate to-be-translated words when they are advanced in their training.

\subsubsection{Effects of experience}

To analyse effects of experience, the results of the interpreting trainees after training were compared with those of professional interpreters. The accuracy rate was 93.4\% for trainees after training and $100 \%$ for professionals. Since there was a ceiling effect for the group of professionals, no further statistical test could be performed to compare these results due to the lack of data variability.

As before, only accurate trials were included in the analysis of translation latencies. A linear mixed model was created with sliding contrasts to estimate parameters and Satterthwaite approximations to establish $p$ values. As in the case of comparing trainees before and after training, the model included group, context, direction, two-way and three-way interactions between the factors as fixed factors, and items and participants as random intercepts. Log-transformed reaction times were used in the model. This means that the coefficients and standard 
errors provided below are log-transformed values. However, for convenience, the means and standard deviations for specific conditions are provided in ms. All means without $\log$ transformations are included in Table 3 and illustrated in Figure 2.

Significant differences $(\beta=.03, S E=0.01, t=23.83, p<.001)$ were found between the HC $(M=740, S D=426)$ and NC conditions $(M=984, S D=394)$, as well as between the NC and LC conditions $(M=1045, S D=563)(\beta=.03, S E=0.01$, $t=2.42, p<.05)$. Thus, the HC effect was $244 \mathrm{~ms}$, whereas the LC cost was $61 \mathrm{~ms}$ as compared to the NC condition. There was also the main effect of direction $(\beta=.03, S E=0.01, t=2.98, p<.01)$ : that is, B-A translation latencies $(M=906$, $S D=473)$ were $31 \mathrm{~ms}$ shorter than A-B latencies $(M=937, S D=499)$.

A significant two-way interaction was found between two levels of context ( $\mathrm{HC}$ and $\mathrm{NC})$ and direction $(\beta=.07, S E=0.03, t=2.50, p<.05)$. This suggests a more efficient use of context constraint in $\mathrm{A}$ as opposed to $\mathrm{B}$ (translation latencies in the $\mathrm{L} 1-\mathrm{L} 2$ direction were $722 \mathrm{~ms}$ for $\mathrm{HC}$ and $1001 \mathrm{~ms} \mathrm{NC}$, whereas in the L2-L1 direction they were $758 \mathrm{~ms}$ for $\mathrm{HC}$ and $965 \mathrm{~ms}$ for $\mathrm{NC}$ ).

There was a significant two-way interaction between two levels of context (HC and NC) and group $(\beta=.07, S E=0.03, t=2.47, p<.05)$ (translation latencies were $732 \mathrm{~ms}$ for $\mathrm{HC}$ and 1000 for $\mathrm{NC}$ for the advanced trainees and $747 \mathrm{~ms}$ for $\mathrm{HC}$ and 970 for $\mathrm{NC}$ for professional interpreters).

A significant three-way interaction was also found between group, direction and two levels of context (LC and NC) $(\beta=.13, S E=0.06, t=2.32, p<.05)$ (this interaction is illustrated in Figure 2). These interactions will be explained further in the discussion section.

\subsection{Discussion}

The aim of the present study was to unravel the effects of interpreter training and experience on word-translation latency, word-translation accuracy and anticipation. The objective was to investigate the extent to which interpreting practice modulates both accuracy and speed of lexical access in both translation directions.

The analysis of the accuracy data and the reaction times data shows a similar pattern: the trainees performed more accurately and faster after training than before training. Thus, the main effect of training has been found as predicted and is in line with the results of other longitudinal studies on trainees (Bartłomiejczyk 2010; Chmiel 2007; Hervais-Adelman et al. 2015) and one cross-sectional study by García et al. (2014). Owing to a ceiling effect (maximum accuracy achieved by professionals), we cannot conclude about any effect of experience on accuracy. Contrary to my predictions, there was no main effect of experience in word- 
translation latencies, because the trainees after training and the professional interpreters were equally fast when translating words. The current findings are in fact in line with a study by García et al. (2014), who also used a word-translation task. They explained the lack of group difference between professionals and advanced trainees with a potential ceiling effect and suggested that cross-linguistic lexical links become much strengthened at advanced pre-professional levels of translation practice. The current pattern of findings also suggests that word-translation performance might increase with training and reach a ceiling level and might not improve any further with experience.

The training effect shown in word-translation accuracy and latency points to the importance of interpreter training in the modulation of lexical processing. García et al. (2014) speculate that this might be due to the fact that training heightens sensitivity towards meaning similarities and differences between translation equivalents and therefore reorganises cross-linguistic connections (a mechanism stipulated by Duyck and Brysbaert 2008). This reorganisation might be mainly the effect of training and might not be modulated later as a function of experience. Therefore, it would seem that in order to discover whether interpreting experience influences lexical processing, and in what way or ways, more difficult words or tasks and more complex processes should be studied (for example, one could manipulate the frequency, concreteness or cognate status of stimulus words - in the present study, the stimuli were all high-frequency concrete noncognates).

In order to reveal any modulation effect of training and experience on anticipation, the context constraint was manipulated in the present study to find out to what extent high semantic constraint might be used more to the interpreters' advantage and help them anticipate the sentence-final word. The reaction times data brought similar results for the comparison of trainees and professionals. Translations were the fastest in the HC condition and the slowest in the LC condition. Thus, high semantic constraint significantly shortened translation latencies and this anticipation effect exceeded $250 \mathrm{~ms}$ in both analyses (that is, comparing trainees before and after training and comparing trainees after training with professionals). This result supports previous findings (Chmiel 2016; Hodzik 2012; Schwartz \& Kroll 2006; van Hell \& de Groot 2008).

On the other hand, the cost of the LC as compared to the translation of isolated words exceeded $60 \mathrm{~ms}$ in both analyses. This partially supports the findings by van Hell and de Groot (2008) that the HC gain and the LC cost in the word-translation task occurred in one direction only (B-A). These results might be explained in the following way: the anticipation mechanism is at play when a sentence is processed; a semantically constrained context limits the number of plausible sentence-final words and their translation equivalents; thus, a transla- 
tion equivalent is more readily available when the sentence ends in a predictable way. This leads to the HC gain, which is in line with van Hell and de Groot (2008) and the Revised Hierarchical Model (Kroll \& Stewart 1994).

When the processed sentence has an unconstrained context, various plausible words are activated and when the sentence-final word becomes known, all the activated candidates apart from the appropriate translation equivalent have to be inhibited, which generates costs (in line with the Inhibitory Control Model; Green 1998). In the NC condition, no pre-activation takes place as no sentence context is available.

Was this pattern of results modulated by interpreter training or experience? Contrary to the predictions, no context by group interaction was found in the model comparing trainees before and after training, which suggests that training does not modulate anticipation in semantically constrained sentences. However, a context by group interaction was found when comparing professionals to trainees after training. Contrary to my predictions, the HC facilitation effect was stronger for the advanced trainees than for the professionals. Surprisingly, the professionals were faster in the $\mathrm{NC}$ condition, whereas the trainees were faster in the $\mathrm{HC}$ condition. The interaction seems to be driven by longer latencies manifested in the NC condition by the advanced trainees. In addition, it seems that the change of context (from $\mathrm{HC}$ to $\mathrm{NC}$ ) brings about more change in the translation latencies for the trainees than for the interpreters.

It is difficult to explain this counter-intuitive result. A tentative explanation might be that owing to the recency of their training, ${ }^{1}$ the trainees have been made more aware of the importance of anticipation and have become more sensitive to semantic cues than professionals. However, this is a speculative explanation and replication studies with larger samples are needed to probe the issue further.

Finally, directionality was also manipulated in the study. In general, an L2-L1 advantage, typical of less-proficient bilinguals, was found for all the groups in line with previous studies on directionality in interpreting that involved different tasks (Chang 2005; Donovan 2005; Gran \& Fabbro 1988; Mead 2005). Despite the proficient use of languages in interpreting, the strength of interlingual connections in two directions does not achieve symmetry, contrary to what studies on proficient bilinguals show (Christoffels et al. 2006). However, the study by Christoffels et al. (2006) involved word translation in the NC condition only, whereas the present study revealed an interesting interaction between group, context and direction that is examined more closely below.

1. Anticipation is considered to be an important skill and various anticipation exercises are included in the interpreter training programme offered to the student participants in this study. 
First, it is important to look into two-way context by direction interactions in order to reveal more about the nature of anticipation. Similar interactions between context and direction were found when comparing the trainees before and after training (in both accuracy and latency analysis) and when comparing the advanced trainees with the professional interpreters. It would seem that context constraint differentially modulates translation performance so far as the two directions are concerned. In the $\mathrm{HC}$, the participants performed better in $\mathrm{A}-\mathrm{B}$, whereas in the NC the data reflected the main translation direction effect (B-A translations were faster). This strongly suggests an A language advantage in anticipation: the participants benefitted more from the context constraint in their A language, and this corroborates the findings by Jörg (1997), Kurz and Färber (2003) and Bartłomiejczyk (2008). Owing to stronger word-concept mappings in L1 (according to the Revised Hierarchical Model) and more features activated for L1 words (according to the Distributed Feature Model), predicted words are preactivated and response times are shorter in the A-B direction. This is true for all groups and no evidence was found to confirm the modulation of this effect by either interpreter training or experience.

The three-way interaction between group, direction and two levels of context ( $\mathrm{LC}$ and NC) seems to suggest that the advanced trainees manifested an LC cost in $\mathrm{A}-\mathrm{B}$ direction whereas the professional interpreters showed no such language asymmetry in the LC condition. It is probable that when anticipation is not possible due to LC and many potential candidates are pre-activated, the professionals are faster at choosing the appropriate translation equivalent. This might be due to their more efficient inhibition of non-fitting L1 candidates, which in turn might result from higher resting activation levels of $\mathrm{L}_{1}$ words in the advanced trainees as compared to the professional interpreters, as posited by the Inhibitory Control Model (Green 1998). It is also fair to say that the trainees' LC cost in L1-L2 direction was not due to a typical L2 word-production disadvantage because they manifested equal response times for both directions in the NC condition. More studies are needed to examine the ways in which interpreting experience might modulate the inhibition effect.

In general, we see a clear trend in the shortening of A-B translation latencies and in the reduction of the translation direction asymmetry with increasing exposure to interpreting practice. The trainees showed this asymmetry in two conditions (NC and LC) before training and in one condition (LC) after training, whereas the professionals showed no such asymmetry. It would seem that in the case of late L2 speakers (as was the case with the participants in this study) interpreter training influences L1-L2 links much more than L2-L1 links, probably because the latter are strong anyway. Further studies are needed to support this observation. 


\section{Conclusions}

This study aimed to examine the ways in which conference interpreting practice modulates word-translation accuracy, latency and anticipation. The objective was to distinguish between the effect of training and the effect of experience by testing professional interpreters, on the one hand, and interpreter trainees at the beginning and at the end of their training, on the other. Taken together, the findings suggest that word-translation accuracy and latency improve as a result of interpreter training, but they are no longer enhanced in the course of professional interpreting practice. In general, all the groups manifested anticipation in the form of shortened translation latencies in semantically constrained sentences. Contrary to the predictions, no evidence was found to substantiate the claim that either training or experience boosts anticipation. However, anticipation was found to be modulated by the direction of translation - the anticipation effect was stronger for all groups in the L1-L2 direction, thus showing an A-language advantage in anticipation. Although these professional interpreters and advanced trainees can be regarded as proficient L2 language users, they still manifested an $\mathrm{L}_{2}-\mathrm{L} 1$ directionality advantage typical of less-proficient $\mathrm{L}_{2}$ users. The inclusion of the LC condition has brought some novel insights into the modulation of inhibition as a result of interpreter experience. The LC cost decreased with experience, suggesting a more efficient inhibition mechanism, a finding that deserves further enquiry. It might be the case that the professional interpreter advantage in lexical processing results not from the activation mechanism involved in anticipation but from the inhibition mechanism involved in the selection of the proper translation equivalent. It is also probable that this effect stems from proficient language use that might also be typical of other language professionals. In future studies, therefore, interpreters could be compared with other proficient language users, such as L2 teachers. In general, there is no doubt that owing to their specific use of languages, interpreters and trainees are interesting populations to study and they may shed more light on the way in which lexical processing may be reorganised according to specific bilingual experience.

\section{Funding}

This research was funded by the Polish National Science Centre, grant no. DEC-2013/11/B/ HS6/o1539, by the Polish Ministry of Science and Higher Education, grant no. N N104 010637 and the AMU School of Languages and Literatures. 


\section{References}

Adamowicz, A. (1989). The role of anticipation in discourse: Text processing in simultaneous interpreting. Polish Psychological Bulletin 20 (2), 153-160.

Altarriba, J., Kroll, J.F., Sholl, A. \& Rayner, K. (1996). The influence of lexical and conceptual constraints on reading mixed-language sentences: Evidence from eye fixations and naming times. Memory and Cognition 24 (4), 477-492. https://doi.org/10.3758/BF03200936

Barr, D. J., Levy, R., Scheepers, C. \& Tily, H. J. (2013). Random effects structure for confirmatory hypothesis testing: Keep it maximal. Journal of Memory and Language 68 (3). https://doi.org/10.1016/j.jml.2012.11.001

Bartłomiejczyk, M. (2008). Anticipation: A controversial interpreting strategy. In B. Lewandowska-Tomaszczyk \& M. Thelen (Eds.), Translation and meaning. Part 8. Maastricht: Zuyd, 117-126.

Bartłomiejczyk, M. (2010). Effects of short intensive practice on interpreter trainees' performance. In D. Gile, G. Hansen \& N. Pokorn (Eds.), Why translation studies matters. Amsterdam: John Benjamins, 183-194. https://doi.org/10.1075/btl.88.16bar

Bates, D. (2007). Linear mixed model implementation in lme4. Manuscript, University of Wisconsin-Madison.

Bates, D., Kliegl, R., Vasishth, S. \& Baayen, H. (2015). Parsimonious mixed models. arXiv preprint. arXiv:1506.04967.

Chang, C-C. (2005). Directionality in Chinese/English simultaneous interpreting: Impact on performance and strategy use. $\mathrm{PhD}$ dissertation, University of Texas at Austin.

Chernov, G. V. (1979). Semantic aspects of psychological research in simultaneous interpretation. Language and Speech 22, 277-295. https://doi.org/10.1177/002383097902200308

Chernov, G.V. (1992). Conference interpretation in the USSR: History, theory, new frontiers. Meta 37 (1), 149-162. https://doi.org/10.7202/002227ar

Chernov, G. V. (2004). Inference and anticipation in simultaneous interpreting: A probabilityprediction model. Amsterdam: John Benjamins. https://doi.org/10.1075/btl.57

Chmiel, A. (2007). Focusing on sense or developing interlingual lexical links? Verbal fluency development in interpreting trainees. In P.A. Schmitt \& H.E. Jüngst (Eds.), Translationsqualität. Frankfurt am Main: Peter Lang.

Chmiel, A. (2016). Directionality and context effects in word translation tasks performed by conference interpreters. Poznań Studies in Contemporary Linguistics 52 (2), 269-295. https://doi.org/10.1515/psicl-2016-0010

Christoffels, I., de Groot, A.M.B. \& Kroll, J.F. (2006). Memory and language skills in simultaneous interpreters: The role of expertise and language proficiency. Journal of Memory and Language 54 (3), 324-345. https://doi.org/10.1016/j.jml.2005.12.004

De Bot, K. (2000). Simultaneous interpreting as language production. In B. Englund Dimitrova \& K. Hyltenstam (Eds.), Language processing and simultaneous interpreting: Interdisciplinary perspectives. Amsterdam: John Benjamins, 65-88. https://doi.org/10.1075/btl.40.06bot

De Feo, N. (1993). Strategie di riformulazione sintetica nell'intepretazione simultanea dall'inglese in italiano: un contributo sperimentale. Unpublished thesis, University of Trieste. 
de Groot, A.M.B. \& Poot, R. (1997). Word translation at three levels of proficiency in a second language: The ubiquitous involvement of conceptual memory. Language Learning 47, 215-264. https://doi.org/10.1111/0023-8333.71997007

DeLong, K.A., Troyer, M. \& Kutas, M. (2014). Pre-processing in sentence comprehension: Sensitivity to likely upcoming meaning and structure. Language and Linguistics Compass 8 (12), 631-645. https://doi.org/10.1111/Inc3.12093

Denissenko, J. (1989). Communicative and interpretative linguistics. In L. Gran \& J. Dodds (Eds.), The theoretical and practical aspects of teaching conference interpretation. Udine: Campanotto, 155-158.

Díaz-Galaz, S., Padilla, P. \& Bajo, M.T. (2015). The role of advance preparation in simultaneous interpreting: A comparison of professional interpreters and interpreting students. Interpreting 17 (1), 1-25. https://doi.org/10.1075/intp.17.1.01dia

Dijkstra, T.O.N., Wahl, A., Buytenhuijs, F., Van Halem, N., Al-Jibouri, Z., De Korte, M. \& Rekké, S. (2019). Multilink: A computational model for bilingual word recognition and word translation. Bilingualism: Language and Cognition 22 (4), 657-679. https://doi.org/10.1017/S1366728918000287

Dillinger, M. (1994). Comprehension during interpreting: What do interpreters know that bilinguals don't? In S. Lambert \& B. Moser-Mercer (Eds.), Bridging the gap: Empirical research in simultaneous interpretation. Amsterdam: John Benjamins, 155-188. https://doi.org/10.1075/btl.3.14dil

Donovan, C. (2005). Teaching simultaneous interpretation into B: A challenge for responsible interpreter training. Communication and Cognition. Monographies 38 (1-2), 147-166.

Duyck, W. \& Brysbaert, M. (2008). Semantic access in number word translation: The role of crosslingual lexical similarity. Experimental Psychology 55 (2), 102-112. https://doi.org/10.1027/1618-3169.55.2.102

Federmeier, K.D. \& Kutas, M. (1999). A rose by any other name: Long-term memory structure and sentence processing. Journal of Memory and Language 41 (4), 469-495. https://doi.org/10.1006/jmla.1999.2660

Foucart, A., Martin, C.D., Moreno, E. M. \& Costa, A. (2014). Can bilinguals see it coming? Word anticipation in L2 sentence reading. Journal of Experimental Psychology: Learning, Memory and Cognition 40 (5), 1461-1469. https://doi.org/10.1037/aoo36756

Foucart, A., Ruiz-Tada, E. \& Costa, A. (2015). How do you know I was about to say "book"? Anticipation processes affect speech processing and lexical recognition. Language, Cognition and Neuroscience 30 (6), 768-78o. https://doi.org/10.1080/23273798.2015.1016047

Frank, S.L., Otten, L. J., Galli, G. \& Vigliocco, G. (2015). The ERP response to the amount of information conveyed by words in sentences. Brain and Language 140, 1-11. https://doi.org/10.1016/j.bandl.2014.10.006

Frisson, S., Rayner, K. \& Pickering, M. J. (2005). Effects of contextual predictability and transitional probability on eye movements during reading. Journal of Experimental Psychology: Learning, Memory and Cognition 31 (5), 862-877. https://doi.org/10.1037/0278-7393.31.5.862

García, A.M., Ibáñez, A., Huepe, D., Houck, A.L., Michon, M., Lezama, C. G., Chadha, S. \& Rivera-Rei, A. (2014). Word reading and translation in bilinguals: The impact of formal and informal translation expertise. Frontiers in Psychology 5, 1302. https://doi.org/10.3389/fpsyg.2014.01302

Gile, D. (2009). Basic concepts and models for interpreter and translator training. Amsterdam: John Benjamins. https://doi.org/10.1075/btl.8 
Gran, L. \& Fabbro, F. (1988). The role of neuroscience in the teaching of interpretation. The Interpreters' Newsletter 1, 23-41.

Green, D.W. (1998). Mental control of the bilingual lexico-semantic system. Bilingualism: Language and Cognition 1 (2), 67-81. https://doi.org/10.1017/S1366728998000133

Heij, W.L., Hooglander, A., Kerling, R. \& van der Velden, E. (1996). Nonverbal context effects in forward and backward word translation: Evidence for concept mediation. Journal of Memory and Language 35 (5), 648-665. https://doi.org/10.1006/jmla.1996.0034

Hervais-Adelman, A., Moser-Mercer, B. \& Golestani, N. (2015). Brain functional plasticity associated with the emergence of expertise in extreme language control. Neuroimage 114, 264-274. https://doi.org/10.1016/j.neuroimage.2015.03.072

Hodzik, E. (2012). Predictive processes during simultaneous interpreting from German into English. Paper presented at the Looking at Language Acquisition Workshop, Cambridge.

Jörg, U. (1997). Bridging the gap: Verb anticipation in German-English simultaneous interpreting. In M. Snell-Hornby, Z. Jettmarová \& K. Kaindl (Eds.), Translation as intercultural communication. Amsterdam: John Benjamins, 217-228. https://doi.org/10.1075/btl.20.22jor

Kohn, K. \& Kalina, S. (1996). The strategic dimension of interpreting. Meta 41 (1), 118-138. https://doi.org/10.7202/003333ar

Kroll, J.F. \& Stewart, E. (1994). Category interference in translation and picture naming evidence for asymmetric connections between bilingual memory representations. Journal of Memory and Language 33 (2), 149-174. https://doi.org/10.1006/jmla.1994.1008

Kroll, J.F., Michael, E., Tokowicz, N. \& Dufour, R. (2002). The development of lexical fluency in a second language. Second Language Research 18 (2), 137-171. https://doi.org/10.1191/0267658302sr2010a

Kroll, J.F., van Hell, J.G., Tokowicz, N. \& Green, D.W. (2010). The Revised Hierarchical Model: A critical review and assessment. Bilingualism: Language and Cognition 13 (3), 373-381. https://doi.org/10.1017/S136672891000009X

Kujałowicz, A., Chmiel, A., Rataj, K. \& Bartłomiejczyk, M. (2008). The effect of conference interpreting training on bilingual word production. Paper presented at the Poznań Linguistic Meeting.

Kurz, I. \& Färber, B. (2003). Anticipation in German-English simultaneous interpreting. Forum 1 (2), 123-150. https://doi.org/10.1075/forum.1.2.06kur

Kutas, M., DeLong, K.A. \& Smith, N.J. (2011). A look around at what lies ahead: Prediction and predictability in language processing. In M. Bar (Ed.), Predictions in the brain: Using our past to generate a future. Oxford: Oxford University Press, 190-207. https://doi.org/10.1093/acprof:0so/9780195395518.003.0065

Kutas, M. \& Federmeier, K.D. (2007). Event-related brain potential (ERP) studies of sentence processing. In M.G. Gaskell (Ed.), The Oxford handbook of psycholinguistics. Oxford: Oxford University Press.

Lederer, M. (1981). La traduction simultanée: expérience et théorie. Paris: Minard.

Lemhöfer, K. \& Broersma, M. (2012). Introducing LexTALE: A quick and valid Lexical Test for Advanced Learners of English. Behavioral Research Methods 44 (2), 325-343. https://doi.org/10.3758/s13428-011-0146-o

Lim, H-O. (2005). Working into the B Language: The condoned taboo? Meta 50 (4). https://doi.org/10.7202/019870ar

Liu, M., Schallert, D.L. \& Carroll, P.J. (2004). Working memory and expertise in simultaneous interpreting. Interpreting 6 (1), 19-42. https://doi.org/10.1075/intp.6.1.04liu 
McDonald, S.A. \& Shillcock, R.C. (2003). Low-level predictive inference in reading: The influence of transitional probabilities on eye movements. Vision Research 43 (16), 1735-1751. https://doi.org/10.1016/So042-6989(03)00237-2

Mead, P. (2005). Directionality and fluency: An experimental study of pausing in consecutive interpretation into English and Italian. Communication and Cognition. Monographies 38 (1-2), 127-146.

Moser-Mercer, B. (1997). Process models in simultaneous interpretation. In C. Hauenschild \& S. Heizmann (Eds.), Machine translation and translation theory. The Hague: Mouton de Gruyter, 3-18. https://doi.org/10.1515/9783110802474.3

Nicodemus, B. \& Emmorey, K. (2013). Direction asymmetries in spoken and signed language interpreting. Bilingualism: Language and Cognition 16 (3), 624-636. https://doi.org/10.1017/S1366728912000521

North, B. (2014). Putting the Common European Framework of Reference to good use. Language Teaching 47 (2), 228-249. https://doi.org/10.1017/S0261444811000206

Otten, M. \& Van Berkum, J. J.A. (2008). Discourse-based word anticipation during language processing: Prediction or priming? Discourse Processes 45 (6), 464-496. https://doi.org/10.1080/01638530802356463

Przepiórkowski, A., Bańko, M., Górski, R. L. \& Lewandowska-Tomaszczyk, B. (2012). Narodowy Korpus Języka Polskiego. Warszawa: Wydawnictwo Naukowe PWN.

$\mathrm{R}$ Development Core Team. (2013). R: A language and environment for statistical computing. Vienna: R Foundation for Statistical Computing.

Riccardi, A. (1998). Interpreting strategies and creativity. In A. Beylard-Ozeroff, J. Králová, \& B. Moser-Mercer (Eds.), Translators' strategies and creativity. Amsterdam: John Benjamins, 171-180. https://doi.org/10.1075/btl.27.24ric

Schneider, W., Eschman, A. \& Zuccolotto, A. (2002). E-Prime user's guide. Pittsburgh: Psychology Software Tools Inc.

Schwartz, A. I. \& Kroll, J.F. (2006). Bilingual lexical activation in sentence context. Journal of Memory and Language 55 (2), 197-212. https://doi.org/10.1016/j.jml.2006.03.004

Schwieter, J. W. \& Ferreira, A. (2014). Underlying processes of L1 and L3 word translation: Exploring the semantic relatedness effect. In A. Ferreira \& J.W. Schwieter (Eds.), The development of translation competence: Theories and methodologies from psycholinguistics and cognitive science. Newcastle upon Tyne: Cambridge Scholars Publishing, 87-106.

Sedivy, J. C., Tanenhaus, M. K., Chambers, C. G. \& Carlson, G. N. (1999). Achieving incremental semantic interpretation through contextual representation. Cognition 71 (2), 109-147. https://doi.org/10.1016/So010-0277(99)00025-6

Seeber, K. G. (2001). Intonation and anticipation in simultaneous interpreting. Cahiers de linguistique française 23, 61-97.

Seleskovitch, D. \& Lederer, M. (1989). Pédagogie raisonnée de l'interprétation. Paris: Didier.

Setton, R. \& Motta, M. (2007). Syntacrobatics: Quality and reformulation in simultaneouswith-text. Interpreting 9 (2), 199-230. https://doi.org/10.1075/intp.9.2.04set

Sunnari, M. (1995). Processing strategies in simultaneous interpreting: "Saying it all" vs. synthesis. In J. Tommola (Ed.), Topics in interpreting research. Turku: University of Turku, Centre for Translation and Interpreting, 109-119.

Sunnari, M. (1996). Comparison of expert and novice performance in simultaneous interpreting Proceedings of the XIV World Congress of FIT. Melbourne: AUSIT, 993-1000. 
Szewczyk, J.M. \& Schriefers, H. (2013). Prediction in language comprehension beyond specific words: An ERP study on sentence comprehension in Polish. Journal of Memory and Language 68 (4), 297-314. https://doi.org/10.1016/j.jml.2012.12.002

The British National Corpus, version 3 (BNC XML Edition). 2007. Distributed by Oxford University Computing Services on behalf of the BNC Consortium. http://www.natcorp .ox.ac.uk/

Titone, D., Libben, M., Mercier, J., Whitford, V. \& Pivneva, I. (2011). Bilingual lexical access during L1 sentence reading: The effects of L2 knowledge, semantic constraint, and L1-L2 intermixing. Journal of Experimental Psychology: Learning, Memory and Cognition 37 (6), 1412-1431. https://doi.org/10.1037/aoo24492

Tommola, J. (1987). Facilitation and inhibition of word recognition in skilled reading: Effects of different neutral contexts. Journal of Research in Reading 10 (2), 113-121. https://doi.org/10.1111/j.1467-9817.1987.tboo289.x

Tommola, J. \& Helevä, M. (1998). Language direction and source text complexity: Effects on trainee performance in simultaneous interpreting. In L. Bowker, M. Cronin, D. Kenny \& J. Pearson (Eds.), Unity in diversity: Current trends in translation studies. Manchester: St Jerome, 177-186.

Van Assche, E., Drieghe, D., Duyck, W., Welvaert, M. \& Hartsuiker, R. J. (2011). The influence of semantic constraints on bilingual word recognition during sentence reading. Journal of Memory and Language 64 (1), 88-107. https://doi.org/10.1016/j.jml.2010.08.006

Van Assche, E., Duyck, W. \& Brysbaert, M. (2013). Verb processing by bilinguals in sentence contexts. Studies in Second Language Acquisition 35 (02), 237-259. https://doi.org/10.1017/S0272263112000873

Van Berkum, J. J.A. (2009). The neuropragmatics of 'simple' utterance comprehension: An ERP review. In U. Sauerland \& K. Yatsushiro (Eds.), Semantics and pragmatics: From experiment to theory. Basingstoke: Palgrave Macmillan, 276-316.

Van Besien, F. (1999). Anticipation in simultaneous interpretation. Meta 44 (2), 250-259. https://doi.org/10.7202/004532ar

van Hell, J.G. (2005). The influence of sentence context constraint on cognate effects in lexical decision and translation. Proceedings of the 4th International Symposium on Bilingualism. Somerville, MA: Cascadilla Press, 2297-2309.

van Hell, J.G. \& de Groot, A.M. (2008). Sentence context modulates visual word recognition and translation in bilinguals. Acta Psychologica 128 (3), 431-451. https://doi.org/10.1016/j.actpsy.2008.03.010

Vandepitte, S. (2001). Anticipation in conference interpreting: A cognitive process. Revista Alicantina de Estudios ingleseS / Alicante Journal of English Studies 14, 323-335. https://doi.org/10.14198/raei.2001.14.18

West, R.F. \& Stanovich, K.E. (1978). Automatic contextual facilitation in readers of three ages. Child Development 717-727. https://doi.org/10.2307/1128240 


\section{Address for correspondence}

Agnieszka Chmiel

Department of Translation Studies

Faculty of English

Adam Mickiewicz University in Poznań

ul. Grunwaldzka 6

6o-78o Poznań

Poland

achmiel@amu.edu.pl

\section{Biographical note}

Agnieszka Chmiel is professor and Head of the Department of Translation Studies, Faculty of English, Adam Mickiewicz University, Poznań, Poland. Her research interests include: interpreting studies, lexical processing and memory in interpreting, reading in sight translation, audiovisual translation and audio description. She also works as a freelance conference interpreter. Her latest project focuses on creating the Polish Interpreting Corpus (PINC). 